\title{
TEMPORAL LOBE EPILEPSY PRESENTING WITH DELUSION OF LOVE
}

\section{Tulachan Dibya, Yadav Rajesh and Gurung Bindu}

\begin{abstract}
:
Complex partial seizures are characterized by altered awareness of the self and the environment. Consciousness is retained unless secondary generalization occurs. Apart from the area and automatism patients may also experience odd disturbances of thought, emotion, deza vu, Jamai's vu. depersonalization, derealization or even vivid hallucination of past experience (experiential phenomena). Here we report an adolescent lady presenting with non-convulsive status epileptics manifesting in the form of mood disorder with grandiose delusions of increased ability and identity as well as erotomania.
\end{abstract}

Radioimaging and EEG revealed an epileptic focus originating from the parieto-temporal region. The case report cautions against an organic epileptic seizure that might be mistaken for dissociative, pseudodmentia, paranoid psychosis or even schizophrenia.

Key words: Complex partial seizure, erotomania, grandiose delusion, mental state.

\section{Introduction:}

In 1976 Hughlings jacksons wrote, "an epileptic discharge is defined as an occasional, sudden, excessive, rapid and localized disorder of some part of the cerebral hemisphere ${ }^{3}$. The definition has been modified by Saddok and writes, "Epileptic seizures are sudden involuntary behavioural events associated with either excessive or hypersynchromous electrical discharge in the brain",2 .

The behavioural manifestations are most prominent in seizures of complex partial type which characterized by altered awareness of the self and the environment along with other features of mental faculty which includes consciousness, automatic activities, perception, consciousness, automatic activities, perception, cognition, thought memory, mood and psychomotor activity ${ }^{1}$. Among these temporal lobe seizures are not only the most common but also the most likely to be mistaken for psychiatric disorder. It appears that mesial lobes are involved in integrating sensory input, memory and emotiona and in creating a sense of self Paroxysmal disturbance of the region is therefore most likely to result in disorders of particular interest to the psychiatrist ${ }^{4}$.

The Psychoses and mood disturbances associated with epilepsy are best divided into those related to seizure and those seen inter-ictally in patients with epilepsy. Less commonly an abnormal mental state may be the only sign of non-convulsive status epilepticus and the syndrome of epileptic pseudodemetia is increasingly recognized as reversible cause of cognitive decline ${ }^{1}$. 


\section{Case Report}

An adolescent girl of 19 years, who was a student, was admitted under the Department of Psychiatry and Mental Health in Nobel Medical College, Biratnagar for an acute illness of 17 days duration. She presented with multiple episodes of epileptic seizures associated with significant changes in behaviour, mental state and consequently the overall personality. It was insidious in onset but rapidly progressive over a period of 2 days. Her mood was persistently elated with increased psychomotor activity. Her excitement was so much that she could not stay in one place and had to keep on wondering around or keep on talking with friends on matters of self-importance.

Her content would have grandiose and self-importance ideas of increased ability and identity. She would express that she was very beautiful and intelligent and had completed her post-graduated studies which was obviously not true and accused her friends for being jealous about her, tried to harm her to degrade her.

Another specific content of her thought was delusion of secret love. She was having delusion of being loved by a student in the same university as hers. Though there had been no discussion on this issue with the other person on this matter, she came to know about this when she had lost two photographs, which had been secretly taken by the purported lover.

Apart from this she also claims that four other persons including a campus teacher was secrately in love with her and three of her friends were jealous about this.

On cross checking the information given by the patient the characters existed but the story as a whole was confabulated and consistent with the phenomenological rubric "Pseudologia fantastica".

Laboratory investigations like Complete
Blood Count, Liver Function Test, Rental Function test, Thyroid Function Tests (T3m $\mathrm{T} 5, \mathrm{TSH}$ ) and ECG were with in normal limits.

The EEG showed epileptic discharges from the temporal region and CAT SCAN revealed two circumscribed $0.5 \mathrm{~cm}$ circular ring enhancing sessions in the left parietotemporal lobes.

The final diagnosis made was: Localization related epilepsy due to ring enchancing lesions (Neurocysticercosis) in non-convulsive status epilepticus of complex partial type.

Treatment was started with Sodium Valporate $900 \mathrm{mg} /$ day and the subject had shown significant improvement with gradual amelioration of symptoms.

\section{Discussion:}

Epilepsy need not always present with the typical aura, motor, sensory and autonomic manifestations and focal neurological signs. And this is so much more with temporal love epilepsy. It is consistent with our finding and that of the initial study of epilepsy and psychosis by Slater et al. ${ }^{7}$, where they reported most of the patients suffering form foci of temporal lobe origin.

More over our finding further follows the 1969 study of Flor-Henry ${ }^{8}$ who produced the evidence in favour of special regional association by demonstrating that among temporal lobe epileptics those with psychotic and schizophrenia like symptoms were strongly associated with foci in the dominant rather than in the non-dominant lobe. This important finding had been further confirmed by Perez et $\mathrm{al}^{5}$ and Taylor ${ }^{6}$.

So whenever a person presents with and acute change in behaviour, mood disorder, delusions and memory impairment with even a subtle changes in the premorid personality 
one should be aware of aware of organic disease of the brain that might be predisposing and it should be followed by necessary investigations which is rational and cost effective. Sometimes an abnormal mental state may be the only sign of non-diagnosis is easily overlooked.

Non-convulsive status may take the form of a prolonged seizure, or a rapid succession of brief seizures. In such cases, a protracted period of automatic behaviour may be mistaken for a dissociative fugue or other psychiatric disorders ${ }^{1}$.

\section{Reference:}

1 .Gelder M. Mayou $\mathbf{R}$ and Cowen $\mathbf{P}$. Shorter Oxford Textbook of Psychiatry- $4^{\text {th }}$ $E d$. New York: Oxford University Press.2001

2. Shaddock BJ \& Shaddock VA. Kaplan \& Saddock's Comprehensive Textbook of Psychiatry, Vol.7, Philadelphia: Lippincott Williams \& Wilkins. 2000

3. Bird J \& Robertson M. Psychiatric aspects of Neurological Disorders in:
Seminars in General Adult Psychiatry, Vol 2, (Eds.) Stein G \& Wilkinson G. , PP 1027-1102, 1998. London: Royal College of Psychiatrists.

4. Gloor P. Experiential Phenomena of Temporal lobe Epilepsy Brain, 113, 1673-1694, 1990

5. Perez MM, Trimble MR Murray NNF \& Reider I Epilepsy Psychosis an evaluation of PSE Profiles. British Journal of Psychiatry 146, 155-163, 1985.

6. Taylor DC. Factor influencing the occurance of Schizophrenia like psychosis of epilepsy. Psychological Medicine 5, 249-24, (1975).

7. Slater E, Beard AW \& Glithero E. The Schizophrenia like psychosis of epilepsy. British Journal of Psychiatry 109, 95-150, 1963

8. For-Henry P. Psychosis and temporal lobe epilepsy; a controlled investigation. Epilepsia 10, 363-395, 1969.

Rajesh Yadavand and Bindu Gurung, Medical Officers; Department of Psychiatry \& Mental Health, Nobel Medical College, Biratnagar. Dibya Tulachan, Lecturer, Department of Radiology, Nobel Medical College, Biratnagar. Address of Correspondence: Dr. Rajesh Yadav, Department of Psychaitry and Mental Health, Nobel Medical College, Biratnagar-5, Nepal. 